\title{
QBBEP
}

\section{Aplicação dos recursos vinculados à educação: as verificações do Tribunal de Contas de Mato Grosso}

Nicholas Davies

\footnotetext{
Resumo

Examina procedimentos do Tribunal de Contas (TC) de Mato Grosso para a contabilização da receita e despesa vinculada à Manutenção e Desenvolvimento do Ensino (MDE), pesquisa que pretende abranger todos os Tribunais de Contas do Brasil. Embora a documentação consultada não seja suficientemente detalhada, foi possível constatar equívocos e oscilação nas interpretações do TC. Por exemplo, num ano o TC considerou o percentual mínimo dos impostos (35\%) fixados pela Constituição estadual, porém em outros se baseou, sem nenhuma justificativa, nos 25\% da Constituição federal. Outro equívoco foi incluir na base de cálculo do percentual mínimo receitas que são adicionais a este mínimo, como os convênios e salário-educação. O surpreendente foi constatar a aceitação pelo TC, desde 2004, a partir de consulta formulada pela Secretaria Estadual de Fazenda, de que o imposto de renda dos servidores estaduais e municipais não seria classificado como imposto e, portanto, não entraria na base de cálculo dos impostos. Na classificação das despesas em MDE, o TC não teve uma interpretação uniforme sobre o pagamento dos inativos com o percentual mínimo, ora aceitando-o, ora rejeitando-o. Na questão das renúncias fiscais, que correspondem a centenas de milhões de reais por ano, o governo estadual e o TC não cumpriram a Constituição estadual, pois elas não podem ser subtraídas do montante sobre o qual incide o percentual mínimo vinculado à educação. Outro equívoco do TC foi contabilizar restos a pagar
} 
que sejam pagos no exercício. É um equívoco, porque tais despesas pertencem a exercícios anteriores, mesmo porque suas fontes também a eles pertencem. Em síntese, em conseqüência destes procedimentos equivocados dos governos estaduais e provavelmente dos municipais e sua aceitação pelo TC, é possível estimar em centenas de milhões de reais o prejuízo anual para a educação pública estadual e municipal do Estado de Mato Grosso.

Palavras-chave: financiamento da educação; orçamento da educação; Tribunais de Contas; Mato Grosso.

\section{Abstract \\ Application of resources linked to education: verifications of the audit office of the Brazilian State of Mato Grosso}

The article examines procedures adopted by the Audit Office of the Brazilian State of Mato Grosso to calculate revenue and expenditures linked to the maintenance and development of education (MDE) and is part of a research intending to cover all the Audit Offices in Brazil. Although the documentation consulted was not sufficiently detailed, it was possible to find mistakes and oscillation in the interpretations by Audit Office. For example, in one year, the Office took into account the minimum percentage of 35\% of taxes set by the State Constitution, but in other years, with no justification, it considered the percentage of $25 \%$ stipulated in the Federal Constitution. A further mistake was to include in the minimum percentage revenues that are an addition to the above said minimum. It was surprising to find that the Office has accepted since 2004, after a consultation by the State Treasury Secretariat, that the income tax paid by state and municipal civil servants would not be classified as tax and would not, therefore, be included in the calculation of the percentage linked to education. In the classification of expenditures in MDE, the Office has not adopted a uniform interpretation about the payment of retired education personnel using the funds linked to education (the minimum percentage). In the issue of tax incentives reducing the funds to education and amounting to hundreds of millions of Brazilian reais per year, the State government and the Audit Office have not complied with the State Constitution, for the incentives may not be disregarded in the calculation of funds linked to education. Finally, as a result of these mistaken procedures adopted by state governments and probably by municipal administrations and their acceptance by the Audit Office, it is possible to estimate that the state and municipal education in Mato Grosso lose hundreds of millions of Brazilian reais every year.

Keywords: education funding; education budget; Audit Offices; the Brazilian State of Mato Grosso. 


\section{Introdução}

Este texto examina os procedimentos adotados pelo Tribunal de Contas do Estado de Mato Grosso na verificação da aplicação dos recursos vinculados à educação, sendo parte de uma pesquisa sobre o papel dos Tribunais de Contas (TCs) do Brasil nesta verificação. Foi suscitada pela experiência do autor na análise da aplicação da verba da educação por governos estadual e municipais do Rio de Janeiro e na sua fiscalização por parte do Tribunal de Contas do Estado do Rio de Janeiro (Davies, 1999, 2001b). Essa experiência revelou, entre outras coisas, que a interpretação adotada pelos TCs quanto às receitas e despesas vinculadas à Manutenção e Desenvolvimento do Ensino (MDE) nem sempre coincide com o que parece estar na letra e espírito da lei. A possibilidade de interpretações variadas e mesmo conflitantes por parte dos TCs tem sido confirmada na nossa pesquisa. Por exemplo, enquanto alguns tribunais, como os do Pará, do Maranhão e da Paraíba, não consideram despesas de MDE as realizadas com os inativos da educação, outros adotam posição contrária, como os de Minas, São Paulo e Rio Grande do Sul. A experiência de Cesar Callegari (1997) na análise das contas do governo estadual de São Paulo também confirma a importância do conhecimento sobre tais interpretações, que, materializadas em instruções normativas, resoluções ou deliberações, são na prática mais importantes do que o estipulado na LDB (Lei no 9.394), pois os governos estaduais e municipais procuram seguir (quando o fazem, é claro!) as orientações dos TCs na sua prestação de contas, e não necessariamente as disposições da LDB ou de pareceres e resoluções do Conselho Nacional de Educação (CNE). Daí a importância do estudo dessas interpretações para a avaliação menos imprecisa dos recursos vinculados à MDE.

\section{Referências legais, base empírica e procedimentos}

Esta pesquisa foi iniciada em 1998 e procurou obter as normas editadas pelos TCs desde a Lei Federal no 7.348, de 1985, que regulamentou a Emenda Constitucional Calmon, de 1983, restabelecendo a vinculação de recursos para a educação, eliminada pela Constituição imposta pela ditadura militar em 1967. Tomamos essa Lei como marco inicial porque, desde 1967, não havia vinculação constitucional de recursos (restabelecida apenas para os municípios pela Emenda Constitucional no 1, em 1969) e porque ela vigorou integralmente até dezembro de 1996 (quando foi promulgada a LDB) e parcialmente a partir de janeiro de 1997, segundo o Parecer no 26/97 do CNE. Basicamente, esta Lei no 7.348 foi importante porque definiu as receitas e despesas vinculadas à MDE, conceito que mereceu uma definição menos elástica do que a permitida pela função orçamentária de 'Educação e Cultura', prevista na Lei Federal n 4.320, de 1964, que normatiza a elaboração e execução de orçamentos públicos.

Outra referência legislativa que adotamos foi a Emenda Constitucional $n^{\circ}$ 14 (EC 14), de setembro de 1996, além das Leis nº 9.394 e nº 9.424 (esta última regulamentou o Fundef), ambas de dezembro de 1996. 
Para saber como as contas da educação foram avaliadas desde 1985, solicitamos informações e documentos mediante o envio de correspondência a todos os TCs do Brasil. De modo geral, existe em cada Estado um tribunal que analisa as contas tanto do governo estadual quanto dos municipais, com exceção de Bahia, Ceará, Pará, Goiás, Rio de Janeiro e São Paulo, onde há dois TCs. Na Bahia, no Ceará, no Pará e em Goiás, o TCE (Tribunal de Contas do Estado) examina só as contas estaduais, enquanto o TCM (Tribunal de Contas dos Municípios) cuida só das municipais. O Rio de Janeiro e São Paulo, por sua vez, têm a particularidade de possuir um TC só para as contas da prefeitura da capital, enquanto o TCE analisa as contas do governo estadual e de todas as demais prefeituras. Apesar de enviar as correspondências pelo menos três vezes (fevereiro de 1998, maio de 1999 e janeiro de 2000), nem sempre recebemos resposta. Não recebemos resposta dos TCs dos seguintes Estados: Amazonas, Acre, Bahia (TCM), Ceará (TCE), Piauí, Rio Grande do Norte, Rondônia, Roraima, Rio de Janeiro (TCE e TCM) e Tocantins. Outros negaram o fornecimento de informações e documentos (Minas) ou foram sumários nas informações prestadas (TC da prefeitura de São Paulo, TCE de Alagoas, Amapá, Bahia, Mato Grosso e Mato Grosso do Sul). A lacuna ou precariedade de informações, no entanto, foi parcialmente superada pela obtenção dessas normas e informações relevantes por outras vias, como Internet e Biblioteca do TCM do Rio de Janeiro (TCMRJ).

Também era nosso desejo examinar pareceres concretos dos TCs sobre contas de governos estaduais e municipais, uma vez que a nossa experiência no Estado do Rio revelara a não-coincidência de procedimentos recomendados pelos TCs e os efetivamente seguidos pelos seus técnicos e conselheiros. Infelizmente, a imensa maioria dos TCs não nos enviou tais pareceres, com exceção de Distrito Federal, Goiás (TCE), Pará (TCE) e Santa Catarina, porém a biblioteca do TCMRJ possibilitou o acesso a muitos desses pareceres.

Vale lembrar que, como a documentação a que tivemos acesso no princípio nem sempre esclarecia todas as nossas dúvidas e questionamentos, enviamos novos ofícios a alguns TCs. Alguns responderam às nossas ponderações e pedidos de esclarecimento: Espírito Santo, Paraíba, Sergipe, São Paulo (TCE e TCM), Rio Grande do Sul, Goiás (TCE e TCM), Distrito Federal. Outros não: TCE da Bahia e de Minas Gerais e TCE e TCM do Rio de Janeiro. Por isso, o nosso estudo nem sempre conseguiu responder satisfatoriamente a todas as indagações sobre todos os TCs.

Basicamente, as informações e documentos que procuramos obter junto aos TCs foram as seguintes:

1) Legislação federal, estadual ou municipal adotada pelos TCs para a averiguação das receitas e despesas vinculadas à educação ou, mais precisamente, à MDE, conforme definida na Lei n ${ }^{0}$ 7.348, de 1985, e nos artigos 70 e 71 da LDB. Queríamos saber, por exemplo, o percentual mínimo que os TCs consideravam correto, no caso de o percentual das Constituições estaduais e leis orgânicas ser superior aos 25\% previstos na Constituição Federal (CF) de 1988. Essa nossa 
indagação foi suscitada pela experiência no Estado do Rio de Janeiro, em que prefeituras (por exemplo, Petrópolis, São Gonçalo) cujas leis orgânicas fixavam um valor superior aos 25\% alegavam que o percentual válido era o da CF, não o das leis orgânicas, e contavam com a interpretação favorável do TCE. Além disso, o governo estadual do Rio de Janeiro (na gestão de Brizola) havia obtido em 1993 liminar do Supremo Tribunal Federal suspendendo a eficácia do percentual mínimo de 35\% fixado na Constituição Estadual de 1989, o que significou, na prática, a aceitação dos $25 \%$ pelo TC.

2) Instruções e normas internas elaboradas pelos TCs para o cálculo das receitas e despesas vinculadas à MDE desde a Lei $n^{\circ}$ 7.348. Tais instruções são fundamentais porque os governos estaduais e municipais procuram seguir (quando lhes interessam, é claro) os procedimentos nelas contidos, não necessariamente a Constituição Federal, Estadual ou Lei Orgânica ou a legislação educacional.

3) Definição dos impostos que compõem a base de cálculo do percentual mínimo. Queríamos saber, sobretudo, se a receita da dívida ativa oriunda de impostos (DAI) - sua atualização monetária e as multas e juros de mora sobre a dívida - era computada. Essa questão se deveu ao fato de prefeituras fluminenses não a incluírem e de o TCE não têla contabilizado por muitos anos.

4) Contabilização dos ganhos, complementação federal e rendimentos financeiros com o Fundef, receitas do salário-educação, convênios de natureza educacional (merenda e outros), receitas de serviços prestados por instituições educacionais e operações de crédito para a educação. Eram contabilizados como parte do percentual mínimo ou como acréscimos a ele? Este cálculo é importante porque muitas vezes os governos omitem tais receitas ou as incluem na base de cálculo do percentual mínimo, quando o correto é acrescentá-las integralmente ao mínimo.

5) Critérios de cálculo do valor devido em educação: valores nominais ou valores reais, ou, em outras palavras, os valores devidos são corrigidos monetariamente? Estes critérios são fundamentais numa época de inflação alta e mesmo após a decretação do Plano Real, em julho de 1994, porque a inflação persistiu, embora relativamente baixa.

6) Definição de despesas consideradas como MDE. É fundamental a clareza sobre essa definição porque não raro os governos confundem tais despesas com as realizadas na função orçamentária 'Educação e Cultura', modificada para 'Educação' a partir de 2001, mais ampla do que o conceito de MDE, ou com o órgão responsável pela educação.

7) Critérios de cálculo das despesas em MDE - valores empenhados, liquidados ou pagos no ano. Essa diferenciação é fundamental porque não é incomum os governos considerarem os valores empenhados como os aplicados no ensino, mas cancelarem uma parte de tais empenhos no exercício seguinte, fraudando, assim, os valores aplicados no ensino. 
8) Procedimentos adotados pelos TCs, tendo em vista a implantação obrigatória em 1998 do Fundef, cuja lei de regulamentação previa, no art. 11: "Os órgãos responsáveis pelos sistemas de ensino, assim como os Tribunais de Contas da União, dos Estados e dos Municípios, criarão mecanismos adequados à fiscalização do cumprimento pleno do disposto no art. 212 da Constituição Federal e desta lei [...]".

\section{O TC de Mato Grosso}

No caso do TC de Mato Grosso, o nosso estudo se baseou:

1) nos relatórios e pareceres prévios do TC sobre as contas de 1996 , 1997, 1998, 1999, 2000, 2001, 2004 e 2005 do governo estadual, publicados na revista do TC e/ou disponíveis no sítio do TC (www.tce.mt.gov.br);

2) na Resolução $n^{\circ} 1$, editada pelo TC em 12/8/98, que dispõe sobre mecanismos para a fiscalização do cumprimento do disposto no art. 212 da CF;

3) no Ofício 2.142, que o TC nos enviou em 31/3/98;

4) nos artigos de Ana Duarte (1997), técnica do TC, e Rosana Rodrigues (1998), assessora jurídica do TC, publicados na Revista do Tribunal de Contas do Estado de Mato Grosso;

5) nas informações prestadas em 2005 pelo Sr. Edmar Augusto Vieira, gestor governamental da Secretaria Estadual de Planejamento.

Infelizmente, são pouco úteis os pareceres do TC sobre as contas de 2002 e 2003, disponíveis em seu sítio, pois são muito sucintos e não permitem compreender os procedimentos que utilizou na contabilização da receita e despesa em MDE. Os nossos comentários sobre as contas de 1999 também foram prejudicados, porque o número 18 da revista do TC, com o relatório sobre elas, não continha as páginas 67 a 70, que aparentemente traziam informações importantes sobre a aplicação no ensino.

\subsection{As diferenças de interpretação entre técnicos e instâncias do TC}

Embora nem todos os documentos mencionados sejam suficientemente detalhados e/ou muito esclarecedores, permitem apontar alguns dos procedimentos do TC. Inicialmente, cabe sublinhar as diferenças de interpretação entre técnicos e instâncias do próprio TC. Uma refere-se ao percentual mínimo devido se a Lei Orgânica (LO) prevê um percentual superior aos 25\% da CF: enquanto a técnica Ana Maria de Moraes Duarte (1997, p. 68) recomenda o cumprimento do percentual da LO, caso ele seja maior do que os 25\% fixados pela CF, Rosana Rodrigues (1998), assessora jurídica do TC, é ambígua quanto a essa questão, pois, embora informe que deve prevalecer o percentual da LO, "sob pena de se comprometer a autonomia 
municipal", alega que "não se possa aventar por inconstitucional o procedimento" de aplicação dos 25\%. Ao alegar não ser inconstitucional a aplicação de $25 \%$ pelo prefeito quando a LO prevê um percentual maior, a assessora acaba aceitando o descumprimento da LO.

Esta oscilação se manifestou também no caso do percentual mínimo que o governo estadual deveria aplicar, com base no art. 245 da Constituição Estadual de 1989, que determinou 35\% prioritariamente no ensino fundamental e médio. Por exemplo, o relatório do TC sobre as contas de 1996 informa que o Estado deveria aplicar 35\%, porém só gastou 27,41\%, ou R\$ 232 milhões. Já o relatório sobre as contas de 1997 informa que o TC vem aceitando os 25\%, "não só nas contas do Governo, como nas dos Prefeitos, a despeito das suas Leis Orgânicas fixarem percentuais superiores" (Mato Grosso, TCE, 1999a, p. 126). No relatório sobre as contas de 1998 (Mato Grosso, TCE, 1999b), no entanto, o TC volta a mencionar $35 \%$, porém a sua tabela listando receitas e despesas só se refere a 25\%. A Resolução no 1 (Mato Grosso, TCE, 1998b), por sua vez, só faz referência aos 25\%. Não conheço o fundamento legal deste não acatamento do percentual mínimo fixado pela CE, que contraria também o art. 69 da LDB, segundo o qual o percentual válido seria o fixado nas Constituições Estaduais (para os governos estaduais) e nas Leis Orgânicas (para as prefeituras). Desde então o TC se esqueceu dos 35\% e passou a se basear apenas nos $25 \%$.

Além de não seguir a CE, o TC não levou em consideração a liminar do Supremo Tribunal Federal (STF) negando a inconstitucionalidade dos 35\% argüida em 1990 pelo governo estadual na Ação Direta de Inconstitucionalidade $\mathrm{n}^{\circ} 282-1$, ou seja, o governo estadual continuou sendo obrigado a cumprir os 35\%. O STF só deferiu a liminar relativa à expressão "e os municípios" do art. 245, o que significa que os municípios deixaram de ser obrigados a aplicar os 35\% fixados na Constituição Estadual.

Outra ilegalidade praticada pelo governo estadual foi considerar, pelo menos nas contas de 2001 (Mato Grosso, TCE, 2003, p. 143), que o percentual mínimo de 1\% dos impostos (equivalente a R\$ 22,4 milhões em 2001) vinculados pela CE à educação superior possa ser contabilizado dentro do mínimo de 25\%, quando pela CE o correto é contabilizá-lo fora dos 35\%. Nos relatórios sobre as contas de 1996 e 1998, o TC não contabilizou o 1\% dentro do percentual mínimo. O relatório sobre as contas de 1997 (Mato Grosso, TCE, 1999a, p. 127), por sua vez, não esclarece se os R\$ 12,6 milhões aplicados no ensino superior (1,17\%) foram contabilizados dentro do percentual mínimo vinculado ao ensino fundamental e médio. Tal interpretação equivocada do governo foi endossada pelo parecer do Ministério Público junto ao TC pelo menos nas contas de 1999, cujo parecer estima que o governo teria aplicado $26,62 \%$ dos impostos, com a inclusão do 1,48\% aplicado no ensino superior. Entretanto, nas contas de 2001, o Ministério Público não parece ter incluído o percentual mínimo do ensino superior no cálculo, mesmo com a divergência de cálculo do montante devido entre o governo estadual e o TC. 


\subsection{Os componentes da receita vinculadas à educação}

Com relação aos componentes da receita vinculada à educação - os impostos, a dívida ativa de impostos, suas multas e juros de mora, as receitas vinculadas integralmente à educação e, portanto, adicionais ao percentual mínimo, como os convênios, o salário-educação, e o rendimento financeiro com tais receitas adicionais e, após 1998, o ganho com o Fundef e o rendimento financeiro com suas receitas -, não tivemos acesso a nenhuma resolução ou instrução normativa do TC para saber como ele contabilizou tais receitas pelo menos antes de 1998, e os números da revista do TC anteriores a 1997 não esclarecem tais procedimentos. O primeiro número da revista que oferece algum esclarecimento é o 14, de 1998, que contém o relatório sobre as contas estaduais de 1996, o qual, no entanto, não esclarece se a dívida ativa oriunda de impostos e suas multas e juros de mora são incluídas na base de cálculo do percentual mínimo, nem como são contabilizadas as receitas de convênios e salário-educação, adicionais ao mínimo. É possível que a dívida arrecadada, cujo montante não é significativo, tenha sido, corretamente, contabilizada na base de cálculo, se tomarmos como referência os relatórios sobre as contas estaduais de 1998, 2000, 2001 e 2004.

Quanto às receitas adicionais ao mínimo (convênios, salário-educação) e que não devem ser contabilizadas na base de cálculo, o TC nem sempre é claro. É verdade que o seu Ofício 2.142 (Mato Grosso, TCE, 1998a) informa que tais receitas são excluídas da base de cálculo, ou seja, não poderiam ser contabilizadas para efeito do cálculo do percentual mínimo; no entanto, o relatório do TC sobre as contas de 1998, embora exclua as receitas de convênios (R\$ 11,8 milhões) da base de cálculo, não menciona o salárioeducação, que pode ter sido empregado para pagar despesas que só podem ser financiadas com o percentual mínimo dos impostos, não com o salárioeducação, que não é imposto, mas sim contribuição social. Já o relatório sobre as contas de 2000 corretamente exclui tanto os convênios (R\$ 11,6 milhões) quanto o salário-educação (R\$ 12,8 milhões), o mesmo fazendo o relatório sobre as contas de 2004. Entretanto, o relatório sobre as contas de 1999 aceita, na base de cálculo, a contabilização do salário-educação (R\$ 8,1 milhões) e de convênios (R \$ 1,2 milhão) pagos no exercício. Como o TC também contabilizou, para efeito de cálculo do percentual mínimo em 1999, restos a pagar do salário-educação ( $\mathrm{R}$ \$ 1,6 milhão) e convênios ( $\mathrm{R}$ \$ 1,7 milhão) de 1998, a contabilização equivocada no percentual mínimo totalizou mais de R\$ 12 milhões em 1999.

Com relação aos possíveis rendimentos financeiros obtidos não só com tais receitas adicionais, mas com o total dos impostos vinculados à educação, o TC aparentemente não os contabilizou, se tomarmos como referência os relatórios mencionados acima, embora a sua Resolução no 1 (Mato Grosso, TCE, 1998b) determinasse que todos os saldos disponíveis dos recursos da educação fossem aplicados diariamente em fundos de curto prazo ou em operações de mercado aberto, sendo seus resultados financeiros utilizados exclusivamente na manutenção e no desenvolvimento do ensino. Em outras palavras, o TC não cumpriu a sua própria resolução. 
Esta resolução tampouco esclarece como tais receitas adicionais devem ser contabilizadas, na suposição equivocada de que elas são apenas as oriundas do percentual mínimo de impostos. Equivocou-se também ao não incluir no Fundef os rendimentos financeiros auferidos com sua receita, conforme previsto na Lei Federal no 9.424, de 1996. Outro equívoco da resolução foi não determinar, conforme exigido pela Emenda Constitucional n ${ }^{\circ} 14$, que 15\% dos demais impostos não integrantes do Fundef sejam destinados ao ensino fundamental até 2006.

Em 2004, o TC adotou um procedimento inédito entre os TCs e não adotado em nenhum ano anterior, ao excluir da base de cálculo o imposto de renda dos servidores estaduais e municipais. Respondendo à consulta formulada pelo governo estadual por meio do Processo no 21.953-3/04, o TC entendeu que este imposto representa tão somente "registro contábil" e não se trata de "receita financeira disponível para entrega", entendimento este firmado por unanimidade dos conselheiros do TC, pelo Acórdão $\mathrm{n}^{\circ}$ 1.098/04, de 3/11/04, contrariando as interpretações da Secretaria do Tesouro Nacional, dos demais Tribunais de Contas e do Tribunal de Contas da União. A conseqüência dessa interpretação é que dezenas de milhões de reais deixaram/deixam de ser vinculados não só à educação das redes municipais e estadual como também à saúde, desde 2004.*

\subsection{As renúncias fiscais}

Um outro prejuízo para o financiamento da educação e também da saúde (são os únicos setores que contam com a vinculação constitucional de impostos para o seu financiamento), e não tão visível, são as renúncias fiscais. Segundo o relatório do TC sobre as contas estaduais de 2001, o montante de benefícios e incentivos fiscais teria sido em torno de R \$ 509 milhões em 2000, estimando-se em R $\$ 467$ milhões a renúncia para 2001 (Mato Grosso, TCE, 2003, p. 133). Edmar Vieira (2006), gestor governamental da Secretaria Estadual de Planejamento, em correspondência a mim dirigida, estima a renúncia em R\$ 1 bilhão em 2005, provocada pelos seguintes fundos e que não poderiam ser subtraídas da educação, segundo o $\S 3^{\circ}$ do art. 245 da Constituição Estadual:

1) Fundo Estadual de Transporte e Habitação (Fethab).

2) Fundo Partilhado de Investimentos Sociais (Fupis), criado pela Lei $n^{\circ}$ 8.059/2003, cujo art. $6^{\circ}$ prevê que as empresas que contribuírem ao fundo poderão deduzir até 30\% do saldo devedor do ICMS. Ou seja, o recurso deixa de entrar como receita de impostos (ICMS) e entra, aparentemente, como "Contribuição".

3) Fundo Estadual de Fomento à Cultura do Estado de Mato Grosso, instituído pela Lei $n^{\circ} 8.257$, de 22/12/04. Semelhante ao Fupis, o seu art. $6^{\circ}$ prevê que as empresas que contribuírem ao Fundo Estadual de Fomento à Cultura poderão deduzir, até o limite de 30\% do 
de Mercadorias e sobre Prestações de Serviços de Transporte Interestadual e Intermunicipal e de Comunicação (ICMS) apurado em cada período, os valores efetivamente depositados em benefício do Fundo, nos termos do art. 14 da Lei Complementar Federal no 101, de 4 de maio de 2000.

Sobre o Fethab, o relatório sobre as contas de 2001 aponta uma divergência significativa entre a equipe técnica do TC e o Ministério Público junto ao TC. A equipe técnica contabilizou R \$ 49,3 milhões do Fethab na base de cálculo do percentual mínimo por entender que o Fundo, embora com a nomenclatura de "contribuição", constitui imposto, com base no art. 12, § $2^{\circ}$, da Lei no 7.263/2000, segundo o qual, para fins de apuração e recolhimento de ICMS, o Fethab seria atribuído como crédito a ser reduzido do ICMS (Mato Grosso, 2003, p. 140-141). O Ministério Público, por sua vez, entende que o Fethab seria contribuição, e não imposto (p. 153), e, portanto, não deveria ser incluído na base de cálculo.

A propósito dessas renúncias fiscais que resultam em prejuízo para a educação e a saúde, convém lembrar que nem o governo estadual nem o TC cumprem o $\S 3^{\circ}$ do art. 245 da Constituição Estadual, que prevê que "Nos casos de anistia fiscal ou incentivos fiscais de qualquer natureza, fica o Poder Público proibido de incluir os trinta e cinco por cento destinados à educação." Em outras palavras, tais incentivos, se relacionados com impostos, não podem ser excluídos da base de cálculo vinculada à educação.

\subsection{As despesas em MDE}

Na definição das despesas em MDE, os relatórios do TC não são suficientemente detalhados; portanto, não é possível verificar se elas são realmente de MDE. Por exemplo, a merenda escolar, que não pode ser paga com o percentual mínimo dos impostos, pode ter sido contabilizada como MDE, o que infringiria a LDB. Além disso, o TC comete o equívoco de considerar gastos em órgãos da educação (Secretaria Estadual e Fundo Estadual de Educação) como se fossem sinônimos de gastos em MDE. Ora, nem todo gasto realizado por tais órgãos são de MDE. Um exemplo é o da própria merenda e dos inativos. Assim, é provável que os valores reais gastos em MDE não sejam os indicados nos relatórios.

A principal polêmica do que é ou não MDE é relativa aos inativos, sobre a qual o TC adotou procedimento oscilante. Até 1997 aceitava que eles fossem incluídos no percentual mínimo, embora houvesse divergências no interior do TC. Segundo o relatório do TC sobre as contas de 1997 (Mato Grosso, TCE, 1999a, p. 126-127), "é certo que a matéria é controvertível. Em princípio há de se excluir essas despesas, como bem frisou a comissão no seu alentado Relatório [...]". Porém, argumentou o relator das contas que aceitou a inclusão delas porque a LDB não teria excluído expressamente tais despesas e o seu art. 88 teria dado um prazo de um ano para a União, os Estados, o Distrito Federal e os Municípios adaptarem sua legislação 
educacional. No relatório sobre as contas de 1998 (Mato Grosso, TCE, 1999b), os gastos com inativos ( $\mathrm{R} \$ 24,3$ milhões) foram excluídos, reduzindo o percentual aplicado no exercício para 265,2 milhões, ou 22,9\% da receita líquida de impostos. É possível que o montante aplicado em 1998 seja até menor, porque, segundo o relatório, o governo teria cometido a irregularidade de usar R\$11,9 milhões do Fundef, que entrou em vigor em 1998, para pagar despesas do exercício anterior (1997). A propósito da exclusão dos inativos de MDE, uma Comissão do TC, em resposta à defesa formulada pelo governo estadual sobre o relatório do TC, apresenta um argumento que nunca observamos em documentos de outros TCs, quando afirma, corretamente, que "por analogia, se os recursos do Fundef não podem respaldar despesas com inativos, também estes inativos não podem integrar o grupo de despesas de aplicação na educação." (Mato Grosso, TCE, 1999b, p. 145). Já no relatório sobre as contas de 1999, o TC, sem nenhuma explicação ou justificativa, aceita o pagamento dos inativos com parte dos impostos vinculados ao percentual mínimo. O relatório sobre as contas de 2000 (Mato Grosso, TCE, 2003), por sua vez, é contraditório. Ao mesmo tempo que declara que o governo aplicou 25,26\% e atendeu à exigência constitucional de $25 \%$ dos impostos previstos na CF, apresenta uma tabela, na p. 48, que mostra que este percentual cai para 21,91\% com a exclusão dos dispêndios com inativos (R\$ 76,9 milhões), salário-educação (R\$ 12,8 milhões) e convênios ( $\mathrm{R} \$ 11,6$ milhões). O relatório sobre as contas de 2001 é curioso. A equipe técnica do TC parece excluir os gastos com os inativos (R\$ 42 milhões), mas o conselheiro-relator adota uma posição dúbia, aparentemente aceitando o pagamento dos inativos com o percentual mínimo, embora reconheça que o Parecer CP 26/97 do Conselho Nacional de Educação tenha excluído os inativos de MDE e que o TCU não recomenda o pagamento dos inativos com recursos destinados à MDE. Os relatórios sobre as contas de 2004 e 2005, por sua vez, não mencionam os inativos e é provável que o TC tenha aceitado que o pagamento deles fosse considerado MDE.

Também o Ministério Público junto ao TC, em seus pareceres, não demonstra uniformidade de interpretação nesta questão. Enquanto nas contas de 1999 (Mato Grosso, TCE, 2000, p. 78) e 2001 (Mato Grosso, TCE, 2003, p. 153) é favorável a que os inativos sejam pagos com os recursos vinculados, nas de 2000 adota posição contrária, afirmando que

[...] assiste razão aos auditores da Casa, quando afirmam que os pagamentos dos proventos relacionados aos inativos e pensionistas não devem compor a base de cálculo dos $25 \%$ destinados à manutenção e desenvolvimento do ensino, [...] pois, em consonância com o entendimento do Conselho Nacional de Educação, os inativos e pensionistas não contribuem com as ações de manutenção e desenvolvimento do ensino. [...] A alegação da Sefaz [Secretaria de Fazenda] de que os inativos e pensionistas da Seduc [Secretaria de Educação] estão vinculados a esta Secretaria não se traduz em argumento fortemente válido para autorizar o Sr. Secretário a lançar mão dos recursos específicos da Educação (Mato Grosso, TCE, 2003, p. 53). 


\subsection{A destinação do Fundef}

A falta de uniformidade também caracteriza o TC na interpretação sobre a destinação dos 60\% do Fundef, ora se referindo a professores, ora a profissionais do magistério em exercício no ensino fundamental, o que talvez se deva à falta de consistência da própria legislação federal. Enquanto a Emenda Constitucional no 14 estabelece que pelo menos 60\% do Fundef se destinam ao pagamento de professores em efetivo exercício no ensino fundamental, a Lei no 9.424, que regulamentou o Fundef, em 1996, determinou que pelo menos 60\% são para a remuneração dos profissionais do magistério, categoria que, segundo a Resolução n 3, de 1997, do Conselho Nacional de Educação (Brasil, MEC, 1997), abrange não só professores, como também diretores, supervisores, orientadores, coordenadores e todos aqueles envolvidos em funções tradicionalmente definidas como pedagógicas. Entretanto, apesar dessa oscilação na legislação federal, o TC deveria ter feito uma opção sobre os beneficiáveis pelos 60\%.

A propósito da destinação dos 60\% do Fundef, os pareceres do TC nem sempre deixam claro se o TC verifica efetivamente se os pagos com este percentual estão em exercício no ensino fundamental. Há exceções, no entanto. Segundo a Comissão Técnica do TC, o governo estadual teria usado R\$ 17 milhões do Fundef para pagamento dos professores do ensino médio nas contas de 1999 (Mato Grosso, TCE, 2000, p. 74).

O TC também se equivoca ao usar os termos "valorização" e "remuneração" do magistério como se fossem sinônimos, como fez no relatório sobre as contas de 2001 (Mato Grosso, 2003, p. 140). Ora, 60\% do Fundef para a remuneração dos professores ou profissionais do magistério em exercício no ensino fundamental não garantiram, não garantem, nem garantirão no Fundeb, a valorização, pelo menos no sentido de melhoria salarial, por duas razões básicas.

Uma é que o Fundef é um fundo que não aumentou os recursos para a educação, mas apenas redistribuiu uma parte deles (15\% de alguns impostos), entre o governo estadual e as prefeituras, de acordo com o número de matrículas que tinham no ensino fundamental regular. Nesta redistribuição, alguns ganharam mas outros perderam na mesma proporção. Em Mato Grosso, o governo estadual perdeu para muitas prefeituras, e, portanto, a sua receita com o Fundef correspondeu a um valor inferior à sua contribuição. Em outras palavras, os 60\% tomaram como referência um valor inferior e, portanto, não poderiam melhorar os salários, se o governo estadual se limitasse apenas aos 60\%. Na verdade, segundo vários pareceres do TC, o governo estadual nem mesmo destinou 60\% para tal remuneração em vários anos.

A outra razão é que as receitas de impostos vinculadas à educação mas que não integram o Fundef às vezes (dependendo do Estado ou do município) são maiores ou mesmo bem maiores do que a receita com o Fundef. Por exemplo, segundo o parecer do TC sobre as contas estaduais de 2005 (Mato Grosso, TCE, 2006b), o total de impostos teria sido de R\$3,146 bilhões. Se tomarmos como referência os 35\% dos impostos previstos pela Constituição Estadual prioritariamente para o ensino fundamental e o ensino 
médio, o montante vinculado à MDE seria de R\$ 1,101 bilhão. Como, segundo o parecer, a receita do governo estadual com o Fundef teria sido de cerca de R\$ 350 milhões em 2005, isso significa que os 60\% do Fundef significam em torno de R \$ 212 milhões, menos de 20\% do total de R \$ 1,101 bilhão vinculado à MDE. Mesmo se nos basearmos no percentual mínimo de $25 \%$, adotado pelo governo estadual e aceito equivocadamente pelo TC ao longo de muitos anos, correspondentes a $\mathrm{R} \$ 786$ milhões (25\% de $\mathrm{R} \$ 3,146$ bilhões), os R 212 milhões equivaleriam a apenas $27 \%$ do total vinculado à MDE (R\$ 786 milhões). Este percentual, muito inferior aos 60\%, mostra a fragilidade do Fundef (e também do Fundeb) para qualquer proposta séria de valorização do magistério.

\subsection{Despesa: empenhada, liqüidada ou paga?}

Outra diferença de interpretação refere-se aos valores considerados como aplicados no exercício. Seriam os empenhados ou os pagos? Segundo a técnica Ana Duarte (1997, p. 68), há duas correntes no TC sobre essa questão:

[...] uma desenvolvida pelo senhor presidente, onde as despesas empenhadas que ficarão em restos a pagar poderão ser consideradas como aplicadas na educação, desde que haja disponível financeiro para quitação dessas obrigações. [...] a outra corrente considera apenas a despesa efetivamente paga, não considerando o restos a pagar, mesmo que o município apresente disponível financeiro.

O Inspetor-Geral do TCE, Sr. Miguel Augusto Silva (Mato Grosso, TCE, 1998a), em resposta à consulta que formulamos ao TCE em 1998 (sintetizadas na introdução deste artigo), informa que o TC tem se baseado em despesas pagas, o que pudemos constatar em relatórios do TC sobre as contas estaduais de vários anos e também na Resolução n 1, de 1998.

Este procedimento de se basear nas despesas pagas tem a virtude de combater manobras contábeis dos empenhos em restos a pagar que em exercício posterior são cancelados e, portanto, não são pagos, irregularidade essa cuja prática é reconhecida por conselheiros de dois TCs diferentes. José Gomes Graciosa, do TC do Estado do Rio de Janeiro, por exemplo, reconhece a manobra de emissão de "'empenhos frios', para se atingir o percentual mínimo, que, no entanto, são anulados no exercício subseqüente, através do cancelamento de restos a pagar" (Graciosa, 1999, p. 24). Flávio Régis Xavier de Moura e Castro, do TC de Minas Gerais e presidente da Associação dos Membros dos Tribunais de Contas do Brasil em 1998, por sua vez, explica que "Os restos a pagar têm sido utilizados como artifício para cumprimento de dispositivos constitucionais, como é o caso dos 25\% na manutenção e desenvolvimento do ensino, promovendo o cancelamento das inscrições no exercício seguinte" (Castro, 1999, p. 18).

Entretanto, o TC de Mato Grosso distorce o montante pago ao incluir os restos a pagar de exercícios anteriores. Em 1998, 1999 e 2000, por 
exemplo, foram aceitos pelo TC, respectivamente, os seguintes restos a pagar: R\$ 23 milhões, R\$ 33,2 milhões e R\$ 7,8 milhões. Contraditoriamente, no caso do Fundef, o TC, pelo menos nas contas estaduais de 1998, não aceitou que a sua receita de 1998 financiasse despesas de exercício anterior, citando manual de orientação do MEC que teria determinado que "os critérios e limites estabelecidos pela legislação, com relação ao uso dos recursos do Fundef (e da educação em geral), devem ser observados e cumpridos tomando-se como referência cada exercício" (Mato Grosso, TCE, 1999b, p. 108). Segundo o seu parecer, $R$ \$ 11,9 milhões do Fundef teriam sido utilizados em 1998 para quitar dívidas de exercício anterior.

\section{Conclusões}

Este estudo dos procedimentos do TC para a contabilização da receita e despesa vinculada à MDE permitiu apontar algumas conclusões com impacto negativo no financiamento da educação. Antes de mais nada, cabe ressaltar que a qualidade da análise foi prejudicada pelo pouco detalhamento da documentação, que, mesmo com esta limitação, foi suficiente para identificar algumas fragilidades dos procedimentos do TC. Se ela detalhasse as despesas que considerou de MDE, provavelmente algumas seriam excluídas do legalmente permitido pela LDB, o que reduziria o valor legalmente aplicado. Por exemplo, não esclarece se as despesas com merenda escolar foram contabilizadas dentro do percentual mínimo dos impostos, contabilização não permitida pela LDB. De qualquer maneira, a documentação mostra que o TC adotou interpretações oscilantes ao longo do tempo. Num momento considerou que o percentual mínimo que o governo estadual deveria aplicar era o fixado na Constituição Estadual (35\%), não os 25\% da CF. Posteriormente, passou a aceitar, com base em critérios que desconhecemos, os 25\% da CF. Outra oscilação pode ser observada na definição dos componentes da base de cálculo do percentual mínimo. Em ofício a nós dirigido em 1998, o TC afirmou não contabilizar as receitas extras como as de convênios e salário-educação na base de cálculo do percentual mínimo, porém alguns de seus relatórios contabilizaram tais receitas dentro do mínimo, quando, na verdade, constituem acréscimos ao mínimo. O surpreendente foi constatar a aceitação pelo TC, a partir de consulta formulada pela Secretaria Estadual de Fazenda, que desde 2004 o imposto de renda dos servidores estaduais e municipais não seria classificado como imposto e, portanto, não entraria na base de cálculo dos impostos. Na classificação das despesas em MDE, a principal polêmica, relativa ao pagamento dos inativos com o percentual mínimo, não teve uma interpretação uniforme do TC, que ora aceitou, ora rejeitou tal pagamento com o percentual mínimo. Na questão das renúncias fiscais, que correspondem a centenas de milhões de reais, o governo estadual e o TC não cumpriram a Constituição Estadual, que estipula que elas não podem ser subtraídas do montante sobre o qual incide o percentual mínimo vinculado à educação. Outro equívoco do TC foi contabilizar restos a pagar que sejam pagos no exercício. É um equívoco 
porque tais despesas pertencem a exercícios anteriores, mesmo porque suas fontes também a eles pertencem. Em síntese, em conseqüência destes procedimentos equivocados dos governos estaduais e provavelmente dos municipais e sua aceitação pelo Tribunal de Contas, é possível estimar em centenas de milhões de reais o prejuízo anual para a educação pública estadual e municipal em Mato Grosso. Por último, vale a pena indagar sobre a eficácia do Tribunal de Contas para obrigar o governo estadual a cumprir a lei. Afinal, o governo estadual não parece ter sofrido nenhuma punição, a não ser uma ou outra ressalva do TC, embora tenha continuado praticando as mesmas irregularidades, como a não aplicação de 15\% de todos os impostos no ensino fundamental e de 60\% do Fundef na remuneração do magistério, o uso de recursos do Fundef para pagar despesas de exercício anterior, ou de pagamento dos inativos com uma parte do percentual mínimo vinculado à MDE.

\section{Referências bibliográficas}

BRASIL. Constituição da República Federativa do Brasil. Brasília: Senado Federal. Disponível em: <http://www.senado.gov.br> . Acesso em: out. 2006a.

BRASIL. Emenda Constitucional no 14, de 12/9/96. Modifica os arts. 34, 208, 211 e 212 da CF e dá nova redação ao art. 60 do ADCT (cria o Fundef). Brasília: Presidência da República. Disponível em: < http:// www.planalto.gov.br >. Acesso em: out. 2006b.

BRASIL. Lei no 7.348, de 24/7/1985. Regulamenta a Emenda Constitucional no 24, de dezembro de 1983. Brasília: Presidência da República. Disponível em: < http://www.planalto.gov.br> . Acesso em: out. 2005.

BRASIL. Lei no 9.394, de 20/12/96. Estabelece as diretrizes e bases da educação nacional. Brasília: Presidência da República. Disponível em: <http://www.planalto.gov.br>. Acesso em: out. 2006c.

BRASIL. Lei no 9.424, de 24/12/96. Dispõe sobre o Fundef e dá outras providências. Brasília: Presidência da República. Disponível em: < http:// www.planalto.gov.br>. Acesso em: out. 2006d.

BRASIL. Supremo Tribunal Federal. Liminar sobre a ADIN (Ação Direta de Inconstitucionalidade) 282-1, movida pelo governo estadual de Mato Grosso sobre vários artigos da Constituição Estadual. Disponível em: <http:www.stf.gov.br>. Acesso em: nov. 2006. 
CALLEGARI, Cesar. As verbas da educação. A luta contra a sonegação de recursos do ensino público no Estado de São Paulo. São Paulo: Ed. Entrelinhas, 1997.

CARTA dos técnicos do Ministério da Educação e dos tribunais de contas sobre o Fundef. Brasília, 1\%7/99. 32 p.

CASTRO, Flávio Régis de Moura e. A responsabilidade fiscal e a atuação dos Tribunais de Contas no Brasil. Revista do Tribunal de Contas do Estado de São Paulo, São Paulo, n. 93, ago. 1999. Texto de palestra proferida no III Encontro dos Tribunais de Contas do Brasil, em agosto de 1999.

CONSELHO NACIONAL DE EDUCAÇÃO. Parecer n ${ }^{\circ}$ CP 26/97, de 2 de dezembro de 1997. Interpreta o financiamento da educação na LDB. Brasília, 1997. Disponível em: <http://www.mec.gov.br> . Acesso em: jun. 1998.

. Resolução n ${ }^{\circ}$ CP 3/97, de 2 de dezembro de 1997. Brasília, 1997. Disponível em: <http://www.mec.gov.br> . Acesso em: jun. 1997.

DAVIES, Nicholas. Legislação educacional federal básica. São Paulo: Cortez, 2004a.

. O financiamento da educação no Brasil: novos ou velhos desafios? São Paulo: Xamã, 2004b.

O Fundef e as verbas da educação. São Paulo: Xamã, 2001a.

. O Tribunal de Contas e a educação: quem controla o fiscalizador dos recursos? Brasília: Ed. Plano, 2001b.

. Tribunal de Contas: faz as contas ou faz de conta na avaliação dos gastos governamentais em educação? Revista Brasileira de Estudos Pedagógicos, Brasília, v. 80, n. 194, jan./abr. 1999.

Verbas da educação: o legal x o real. Niterói: Ed. UFF, 2000.

DUARTE, Ana Maria de Moraes. Aspectos Contábeis Privado/Público. Revista do Tribunal de Contas do Estado de Mato Grosso, Cuiabá, n. 13, 1997.

GRACIOSA, José Gomes. Fundef. Rio de Janeiro: Tribunal de Contas do Estado, jun. 1999.

MATO GROSSO. Constituição Estadual de Mato Grosso. Disponível em: $<$ http://www.tce.mt.gov.br>. Acesso em: mar. 2006a. 
MATO GROSSO. Secretaria Estadual de Fazenda. Processo no 21.953/3/04. Consulta ao TCE sobre a classificação do imposto de renda dos servidores como imposto ou registro contábil. Disponível em: < http:// www.tce.mt.gov.br index2.php? $\mathrm{p}=$ decisoesGa $=$ decisoes.phpGids $=3732>$. Acesso em: 2 nov. $2006 b$

MATO GROSSO. Tribunal de Contas do Estado. Acórdão nº 1.098/04, de 3/11/04. Decisão sobre consulta formulada pela Secretaria Estadual de Fazenda sobre a classificação do imposto de renda dos servidores como imposto ou registro contábil. Disponível em: <http://www.tce.mt.gov.br/ index2.php? $\mathrm{p}=$ decisoesGa $=$ decisoes.phpGids $=3732>$. Acesso em: 2 nov. 2006a.

Ofício 2.142, de 31/3/98, do Presidente do TCE, Sr. Djalma Metello Duarte Caldas, acompanhada da resposta do Inspetor-Geral Miguel Augusto A. Silva à consulta por nós formulada ao TCE. Cuiabá, 1998a.

Relatório do TCE sobre as contas estaduais de 2004. Cuiabá. Disponível em: <www.tce.mt.gov.br>. Acesso em: nov. 2006b.

Relatório do TCE sobre as contas estaduais de 2005. Cuiabá. Disponível em: <www.tce.mt.gov.br>. Acesso em: nov. 2006c.

Resolução no 1, de 12/8/1998. Institui mecanismos adequados à fiscalização do cumprimento pleno do disposto no artigo 212 da Constituição Federal, conforme disposto no artigo 11 da Lei no 9.424/96. Cuiabá, 1998b.

Revista do Tribunal de Contas do Estado de Mato Grosso, Cuiabá, n. 14, 1998c. (Contém o relatório do TCE sobre as contas estaduais de 1996).

Revista do Tribunal de Contas do Estado de Mato Grosso, Cuiabá, n. 18, out. 2000. (Contém o relatório do TCE sobre as contas estaduais de 1999).

Revista do Tribunal de Contas do Estado de Mato Grosso, Cuiabá, n. 15, 1999a. (Contém o relatório do TCE sobre as contas estaduais de 1997).

Revista do Tribunal de Contas do Estado de Mato Grosso, Cuiabá, n. 17, 1999b. (Contém o relatório do TCE sobre as contas estaduais de 1998).

Revista do Tribunal de Contas do Estado de Mato Grosso, Cuiabá, n. 20/21/22, jul. 2001/jan. 2003. (Contém o relatório do TCE sobre as contas estaduais de 2000 e 2001). 
RODRIGUES, Rosana Kassar do Valle. Novas diretrizes e bases para a educação nacional. Lei no 9.394, de 20 de dezembro de 1996. Revista do Tribunal de Contas do Estado de Mato Grosso, Cuiabá, n. 16, jul./dez. 1998.

VIEIRA, Edmar. Gestor governamental da Secretaria Estadual de Planejamento. Comunicação sobre renúncias fiscais do governo estadual do Mato Grosso. 2006 (Comunicação eletrônica).

Nicholas Davies, doutor em Sociologia pela Universidade de São Paulo (USP), é professor da Faculdade de Educação da Universidade Federal Fluminense (UFF), Niterói-RJ.

ndavies@uol.com.br

Recebido em 28 de novembro de 2006.

Aprovado em 11 de abril de 2007 